\title{
PARTICIPAÇÃO, DEMOCRACIA E CIDADANIA DOS POVOS INDÍGENAS NO CONTEXTO INTERNACIONAL ATRAVÉS DOS SISTEMAS EUROPEU E INTERAMERICANO DE DIREITOS HUMANOS
}

ROBERTO LUIZ SILVA

Professor Associado (RJU) da Universidade Federal de Minas Gerais - UFMG. Pós-Doutor pela The University of Texas (2005). Pesquisador de Nível II do CNPq. Avaliador Institucional e de Cursos do INEP/SINAES/MEC.roberto-silva@ufmg.br

Keyla Cristina Farias dos Santos

Advogada. Consultora Jurídica da Câmara dos Deputados - DF na Comissão de Direitos Humanos Internacionais. Professora da Universidade Federal do Pará - UFPA . Doutoranda da Universidade Federal de Minas Gerais - UFMG. keylafarias@dir.dout.ufmg.br

\section{Resumo}

Este artigo apresenta a democratização global para a proteção de minorias, através da promoçáo global dos Sistemas Europeu e Interamericano de Direitos Humanos. No plano do Direito Internacional dos Direitos Humanos, essas ideias estão na base do chamado "processo de especificaçáo dos sujeitos de direitos", segundo o qual, além de direitos gerais universais, extensíveis a todos, há necessidade de se reconhecer direitos específicos a determinados grupos vulneráveis dentro da sociedade. Isso com o objetivo de se atingir a igualdade real, ou pelo menos, reduzir as desigualdades de fato existente. Assim, a consolidação da proteção das minorias reflete a situação da necessidade do acesso à ordem jurídica justa de modo a garantir a efetividade de direitos fundamentais e a consolidaçáo plena de acesso à justiça através das cortes internacionais de justiça, que visam a proteção dos Direitos Humanos no contexto internacional.

\section{Palavras-chave}

Proteção; Minorias; Efetividade; Justiça; Cidadania.

\section{Abstract}

This article presents the global democratization for the protection of minorities through the global promotion of European systems and Inter-American Human Rights. 
At the level of international human rights law, these ideas are the basis of so-called "specification process rights of individuals", according to which, in addition to general universal rights extended to all, there is need to recognize specific rights to certain groups vulnerable in society. With the goal of achieving real equality, or at least reduce the existing factual inequalities. Thus, consolidation of protection of minorities reflects the situation of need access to fair legal system to ensure the effectiveness of fundamental rights and the full consolidation of access to justice through the international courts of justice, aimed at protection of human rights the international context.

\title{
Key words
}

Protection; Minorities; Effectiveness; Justice; Citizenship.

\section{Introdução}

Os tratados de direitos humanos têm como objetivo que tais direitos sejam efetivados na jurisdição interna dos Estados que são membros desses tratados ${ }^{1}$, por isso mesmo a questão de direitos humanos é definida como "questão de jurisdição concorrente ou compartilhada" entre a interna e a internacional.

Desde a Carta das Naçóes Unidas assinada em San Francisco nos Estados Unidos no dia 26 de junho de 1945 e que entrou em vigor no dia 24 de outubro de 1945, ficou estabelecido "o princípio novo de que a proteção dos direitos humanos constitui uma questão fundamentalmente internacional" 2 e que, as normas de direito internacional convencional sejam normas imperativas e não derrogáveis, que garantam a ordem pública internacional.

Por outro lado, a mesma Corte Interamericana, em uma de suas opinióes consultivas, declarou:

\begin{abstract}
"Os tratados modernos sobre direitos humanos, em geral, e, em particular, a Convenção Americana, não são tratados multilaterais de tipo tradicional, concluidos em função de um intercâmbio recíproco de direitos, para o beneficio mútuo dos Estados contratantes. Seu objetivo e fim é a proteção dos direitos fundamentais dos seres humanos, independentemente de sua nacionalidade, tanto diante de seu próprio Estado como de outros Estados contratantes. Ao aprovar esses tratados sobre direitos humanos, os Estados se submetem a uma ordem legal na qual eles, para o bem comum, assumem várias obrigaçóes não em relação a outros Estados, mas em relação aos indivíduos sob sua jurisdição".
\end{abstract}

1 BIDART CAMPOS, G. J. La interpretación de los derechos humanos en La jurisdicción internacional y en la jurisdicción interna. La Corte y el sistema interamericano de derechos humanos, p. 39

2 ALEXY, Robert. Teoria dos direitos fundamentais, p. 90; DWORKIN, Ronald. Levando os direitos a sério, p. 41 
Em decorrência dos efeitos produzidos, seria possível dizer que os tratados internacionais de direitos humanos constituem uma fonte de valor maior em relação a qualquer outro pacto convencional: uma escala de direito "superconvencional".

O certo é que depois de 1945, assiste-se a uma expansão do Direito Internacional que penetra nos domínios econômicos, social e cultural se dirige mais diretamente aos indivíduos, além disso, o desenvolvimento dos órgãos supranacionais conhece avanços antes impensáveis e limita em grande escala a soberania estatal.

Como conseqüência, as organizaçóes internacionais e seus mecanismos são modificados porque mudam os sujeitos de direitos não somente os Estados, as fontes e as convençôes, até modificar as relaçôes com o direito interno e os sistemas jurídicos nacionais por causa de uma "mútua influência” entre organização internacional e Constituições.

À luz dessas evoluçóes, pode-se entender por quais razóes os Estados nacionais em geral se vêem coagidos, hoje em dia, e cada vez mais, a levar em conta, em suas decisóes políticas e na política de governo, o direito internacional e a jurisprudência dos tribunais internacionais, para, assim, evitar uma aplicação de suas leis internas de maneira que possa violar as obrigaçóes internacionais de seu país e também para adequar seu direito interno às normas legais internacionais vigentes.

Em 1948, as "regióes" da América no sentido mais amplo começaram a desenvolver a proteção e a promoção dos direitos humanos. Em particular, isso aconteceu quando, em Bogotá na Colômbia, os Estados Membros da Organização dos Estados Americanos OEA adotaram a Declaração Americana de Direitos e Deveres do Homem.

Ainda que a maneira adotada tenha sido apenas uma simples aspiração moral, gradualmente o caráter da Declaração evoluiu até converter-se em um instrumento normativo de pleno valor jurídico, pelo menos com relação aos direitos fundamentais que consagra.

Isso foi possível mediante um processo bastante difícil que incluiu a criação, em 1959, da Comissão Interamericana de Direitos Humanos para promover o respeito aos direitos humanos reconhecidos na Declaração.

Depois da aprovação do Estatuto da Comissão, em 1960, pelo Conselho da OEA e da ampliação de seus poderes em 1965, para que ela pudesse receber também denúncias individuais, a Comissão chegou a ser configurada como o órgão principal para a tutela dos direitos humanos com competência no que se refere a todos os Estados Membros da OEA.

Foi sobre a base de um projeto da mesma Comissão que em 1969, em San José de Costa Rica ${ }^{3}$, adotou-se a Convenção Americana sobre Direitos Humanos, que instituiu

3 O Pacto de San José da Costa Rica foi adotado na Conferência Especializada Interamericana sobre Direitos Humanos, ocorrida em San José em 1969 e foi aprovado pelo Brasil em 1992, pelo Decreto 
pela primeira vez dois órgãos para tutelar os direitos humanos: a mesma Comissão e a Corte.

De fato, a Convenção entrou em vigor somente em 1978 e os dois órgãos funcionaram efetivamente sob suas normas somente depois que a Assembléia-Geral da OEA, celebrada em La Paz na Bolívia em 1979, aprovou seus Estatutos.

Pode-se deduzir que durante vinte anos a Comissão foi o único órgão encarregado de tutelar tais direitos, logo continuou exercitando suas competências também sobre os Estados que não haviam ratificado ou aderido ao Pacto de San José de Costa Rica ${ }^{4}$.

De qualquer forma, atualmente, a função de proteger os direitos humanos é "compartilhada" com a jurisdição obrigatória da Corte.

$\mathrm{O}$ art. 33 da Convenção atribui competências comuns à Corte e à Comissão, porque a ambas compete "conhecer os assuntos relacionados ao cumprimento dos compromissos contraídos pelos Estados Membros da Convenção" ${ }^{5}$. Entretanto, em uma visão complexa do mesmo Pacto de San José de Costa Rica, configura-se uma competência mais ampla e genérica da Comissão, executável espontaneamente, sem necessidade da intervenção ou o requerimento de um terceiro através das seguintes competências de acordo com o art. 41 Convenção:

- estimular a consciência dos direitos humanos nos povos da América;

- formular recomendaçóes, caso seja conveniente aos governos dos Estados Membros, para que sejam adotadas medidas progressivas a favor dos direitos humanos;

- preparar os estudos ou relatórios adequados para o desempenho de suas funçóes;

- solicitar relatórios aos governos dos Estados Membros;

- atender às consultas formuladas por esses últimos na Secretaria-Geral da OEA;

- quando houver petiçôes ou outras comunicações, atuar conforme seus poderes (art. 44-51 Convenção);

- elaborar um relatório anual à Assembléia Geral da OEA.

Legislativo 27, e entrou em vigor internamente em 1992, através da promulgação do Decreto Executivo 678.

4 WATSON, Adam. A evolução da sociedade internacional: uma análise histórica comparativa, p. 428

5 SOARES, Mário Lúcio Quintão. Direitos fundamentais e direito comunitário: por uma metódica de direitos fundamentais aplicada às normas comunitárias, p. 15-198 


\section{Problematização}

Evidenciar que apesar de ser mais definidas e pontuais as funçôes da Corte Interamericana, ela é composta por sete juízes nacionais dos Estados Membros da OEA, eleitos para um cargo de seis anos, renovável apenas uma vez, a título pessoal, entre juristas da mais alta autoridade moral, de reconhecida competência em matéria de direitos humanos e que reúnam as condições requeridas para o exercício das altas funções judiciais, conforme a lei do Estado ao qual pertencem.

Duas são as atribuiçôes essenciais da Corte: a primeira, de natureza "consultiva”, sobre a interpretação das disposiçóes da Convenção Americana e dos tratados concernentes à proteção dos direitos humanos e a segunda de caráter “jurisdicional”.

Os Estados Membros da OEA e seus órgãos principais e a Comissão podem consultar a Corte acerca da interpretação dessa Convenção ou de outros tratados concernentes à proteção dos Direitos Humanos.

Ao contrário, com relação à função propriamente jurisdicional, somente os Estados Membros da Convenção e a Comissão podem submeter um caso à decisão jurisdicional como a sentença da Corte, que é juridicamente vinculante e, além disso, "a parte da sentença que disponha indenização compensatória poderá ser executada no respectivo país pelo procedimento interno vigente para a execução de sentenças contra o Estado"', conforme art. 68 da Convenção de Direitos Humanos.

Por isso mesmo, como as vítimas se encontram impossibilitadas de acessar diretamente a Corte, a Comissão representaria tanto os interesses gerais do sistema de acordo com os direitos humanos estabelecidos na Convenção que possam efetivamente ser tutelados pelo órgão propriamente judicial do sistema interamericano, como os interesses das partes que os tenham solicitado.

Os requisitos que devem ser cumpridos para que a Comissão submeta um caso à Corte não parecem ser regulamentados com relação às suas peculiaridades nem pela Convenção, nem pelo Estatuto ou pelo Regulamento da Comissão, mas parecem ser regulamentados pelas opinióes da mesma Comissão e por aquelas da Corte: é preciso notar nesse contexto que, segundo a Comissão, seria necessário que já tivesse esgotado diante si mesmo o procedimento previsto e tenha sido individuada previamente uma violaçáo de um direito humano estabelecido pela Convençáo, enquanto que, segundo a Corte, pareceria ser critério essencial que o caso náo houvesse sido resolvido amistosamente na Comissão e que este provoque problemas legais controvertidos.

6 JAYME, Fernando G. Direitos humanos e sua efetivação pela Corte Interamericana de Direitos Humanos, p. 98-99. 
Como fica evidente, esse critério amplo utilizado pela Corte se justifica somente à luz de uma tendência a implementar o maior número de medidas para a tutela judicial dos direitos humanos: a Corte expressou também que sua decisão de submeter um caso a sua jurisdição "não é facultativo, mas deve apoiar-se na alternativa que seja mais favorável para a tutela de direitos humanos estabelecidos na Convenção"7.

Por um lado, a doutrina evidencia alguns limites, nos quais Estado afetado deve ter aceitado a jurisdição obrigatória da Corte, seja em geral ou para o caso específico, para que possa ser cumprida a disposiçáo do artigo $62 \$ 1$ da Convenção, segundo o qual nenhum Estado pode ser levado a um tribunal internacional sem seu consentimento.

Por outro lado, segundo outra doutrina, para submeter um caso à decisão da Corte não é necessário que o Estado membro tenha aceitado a competência, ainda que seja evidente que tal requisito seja exigido para o Estado demandado e se este tenha aceitado, mas sob condição de reciprocidade, o requisito vale também para o demandante.

O que parece certo é que submeter-se à competência contenciosa da Corte é um ato voluntário ou consensual que pode manifestar-se em diversas modalidades:

a) de pleno direito;

b) por meio de uma declaração separada especial;

c) incondicionalmente;

d) sob condição de reciprocidade;

e) por um período ou por um caso específico.

O quadro seguinte resume os Estados que até hoje tenham ratificado ou aderido à Convenção e reconhecido e de que maneira a competência da Corte Interamericana, submetendo-se a sua jurisdição.

Dessa forma, os princípios vêm recebendo destaque no ordenamento jurídico por serem o resultado de generalizaçóes que reúnem e organizam conhecimentos anteriores, permitindo, assim, a compreensão e a explicitação correlacionada entre ciência acumulada e realidade conhecida sua teorização têm sido tardias e fragmentárias.

Todavia, dado o caráter predominantemente aplicado do Direito, tanto a formalização de práticas e procedimentos jurídicos como sua teorização têm sido tardias e fragmentárias. Discussões jurídicas mais recentes atribuíram às normas a divisão em princípios e regras.

7 TRINDADE, Antônio Augusto Cançado. A proteção internacional dos direitos humanos e o Brasil (1948-1997): as primeiras cinco décadas, p. 32. 
No cerne da divisão está o entendimento de que princípios são enunciados com alto grau de abstração, cujo conteúdo atinge todo o ordenamento e que podem ser aplicados de diversas maneiras, dependendo do caso concreto, e que regras têm funçáo secundária.

No que tange à garantia dos Direitos Humanos, essa diferenciação é especialmente relevante. Argumentando que princípios orientam todo o ordenamento jurídico, defende-se, em muitos casos, a desnecessidade de legislação específica para proteção de tais direitos, como se o fato de haver princípios que versam abstratamente sobre esse tema bastasse para assegurar sua efetivação. Esquece-se de que, por serem abstratos, os princípios, sem que sejam devidamente regulamentados, podem também acabar conferindo plena liberdade a setores específicos de decisóes para a tomada de medidas que deveriam estar ao alcance de todos aqueles aos quais elas se aplicam. É o que ocorre com as sentenças da Corte Interamericana de Direitos Humanos (CIDH) para a garantia de direitos fundamentais, em especial, das minorias como as populaçôes indígenas. Então, como efetivá-las ante a ausência de regras sobre sua aplicação? ${ }^{8}$.

Essa lacuna legislativa não dá segurança jurídica à garantia dos direitos especificados na tutela concernente à CIDH. A competência da $\mathrm{CIDH}$, recentemente reconhecida pelo Brasil, atribuiu àquele órgão a possibilidade de julgar o país por açóes que tenha cometido e que podem envolver desrespeito a Direitos Humanos, mas cabe ao próprio país determinar o modo de aplicar as sentenças. Contudo, a ausência de legislação nacional nesse sentido deixa ampla margem de discricionariedade ao Estado, que pode, em nome de princípios que considerar prioritários, deixar de aplicar a sentença na sua inteireza ou se escusar de tal aplicação pela ausência de legislação doméstica apropriada, ficando o tutelado à mercê da boa vontade de governantes, sem as devidas e apropriadas garantias.

\section{Justificativa}

\subsection{Direito à Justiça, Justo Processo e Eficiência da Corte Interamericana na Garantia dos Direitos Humanos}

O sistema internacional de proteção dos direitos humanos constitui o legado maior da chamada "Era dos Direitos", que tem permitido a internacionalização dos direitos humanos e a humanização do Direito Internacional Contemporâneo? .

8 JAYME, Fernando G. Direitos humanos e sua efetivação pela Corte Interamericana de Direitos Humanos, p. 90.

9 Thomas Buergenthal, prólogo do livro de Antônio Augusto Cançado Trindade, A proteção internacional dos direitos humanos: fundamentos jurídicos e instrumentos básicos, p. XXXI. No mesmo sentido, afirma Louis Henkin: "O Direito Internacional pode ser classificado como o Direito anterior à 2a Guerra Mundial e o Direito posterior a ela. Em 1945, a vitória dos aliados introduziu uma nova ordem com importantes transformaçôes no Direito Internacional” (Louis Henkin et.al., International law: cases and materials, p.3). 
Norberto Bobbio descreve que, os direitos humanos não nascem todos de uma vez e nem de uma vez por todas ${ }^{10}$. Para Hanna Arendt, os direitos humanos não são um dado, mas um construído, uma invenção humana, em constante processo de construçáo e reconstrução ${ }^{11}$. Refletem um construído axiológico, a partir de um espaço simbólico de luta e ação social.

No entendimento de Joaquim Herrera Flores ${ }^{12}$, os direitos humanos compóe uma racionalidade de resistência, na medida em que traduzem processos que abrem e consolidam espaços de luta pela dignidade humana. Invocando uma plataforma emancipatória voltada à proteção da dignidade humana, que para Carlos Santiago Nino, os direitos humanos são uma construção consciente vocacionada a assegurar a dignidade humana e a evitar sofrimentos, em face da persistente brutalidade humana ${ }^{13}$.

Considerando a historicidade dos direitos, destaca-se a chamada concepção contemporânea de direitos humanos, que veio a ser introduzida pela Declaração Universal de 1948 e reiterada pela Declaração de Direitos Humanos de Viena de 1993.

Essa concepção é fruto da internacionalização dos direitos humanos, que constitui um movimento extremamente recente na história, surgindo a partir do Pós-Guerra, como resposta às atrocidades e aos horrores cometidos durante o nazismo. Apresentando o Estado como o grande violador de direitos humanos, a Era Hitler foi marcada pela lógica da destruição e da descartabilidade da pessoa humana. Em que o legado do nazismo foi condicionar a titularidade de direitos, ou seja, a condição de sujeito de direito, ao pertencimento à determinada raça: a raça pura ariana, que para Ignacy Sachs ${ }^{14}$, o século XX foi marcado por duas guerras mundiais e pelo horror absoluto do genocídio concebido como projeto político e industrial.

É nesse cenário que se vislumbra o esforço de reconstrução dos direitos humanos, como paradigma e referencial ético a orientar a ordem internacional contemporânea, no momento em que, os seres humanos se tornam supérfluos e descartáveis pela lógica da destruição, pensamento este condenável pelo valor à pessoa humana, necessário a reconstrução dos direitos humanos como paradigma ético capaz de restaurar a lógica do razoável.

10 BOBBIO, op. cit, p. 32

11 ARENDT apud LAFER, Celso. A reconstrução dos direitos humanos: um diálogo com o pensamento de Hannah Arendt, São Paulo : Companhia das Letras, 1991. p.134.

12 HERRERA FLORES, Joaquín. Direitos Humanos, interculturalidade e racionalidade de resistência. A Sequência, Florianópolis, v. 23, n. 44, 2002. Disponível em: https://periodicos.ufsc.br/index.php/ sequencia/article/view/15330. Acesso em: 24.03.2015. p.7.

13 NINO, Carlos Santiago. The ethics of human rights. Oxford: Clarendon Press, 1993. p.4

14 SACHS, Ignacy. O desenvolvimento enquanto apropriação dos direitos humanos. Estud. Av., São Paulo, v.12, n. 33, May/Aug. 1998. p.149. 
Essa barbárie do totalitarismo significou a ruptura do paradigma dos direitos humanos, por meio da negação do valor da pessoa humana como valor-fonte do direito. Se a Segunda Guerra significou a ruptura com os direitos humanos, o Pós-Guerra deveria significar a reconstrução destes direitos.

E a perspectiva nazista, derrotada, evidenciou a inviabilidade de se admitir a soberania plena de uma nação guiada pelo Estado de Direito, pois a Declaração Universal conseguiu introduzir com o imprescindível grau de universalismo, um rol de direitos pautados sobre o mesmo valor que é a dignidade da pessoa humana imprescindível para garantir que o Estado náo seja o soberano absoluto na forma de tratamento para com seu nacional, mas garanta a toda Sociedade Internacional o papel importante para a tutela desses direitos.

Thomas Buergenthal descreve que o Direito Internacional dos Direitos Humanos é um fenômeno do pós-guerra e seu desenvolvimento pode ser atribuído às monstruosas violaçóes de direitos humanos na Era de Hitler e à crença de que parte dessas violaçóes poderiam ser prevenidas se um efetivo sistema de proteção internacional de direitos humanos existisse $\mathrm{e}^{15}$.

Cada Estado que adere ao sistema internacional de proteção admite a possibilidade de que uma instância internacional exerça sobre ele o controle de legalidade do núcleo duro dos direitos humanos, desfazendo assim, a teoria da soberania absoluta, desenfreada e desmedida do Estado.

Assim, dentro de uma nova ótica de tutela dos direitos garantidos a todos os cidadãos devidamente reconhecidos pela Sociedade Internacional, estes nascem livres e iguais em oportunidades e direitos, tornando inevitável garantir a hipótese do Estado violar os direitos de seus nacionais, em que possibilitar-se-á recorrer a uma esfera internacional que pudesse intervir na salvaguarda das normas impostas pela Declaração Universal e pelos pactos e tratados decorrentes de suas diretrizes. Além disso, há um sistema global de proteção dos direitos humanos capitaneado pela Organização das Naçóes Unidas para propiciar maior grau de fiscalização desses direitos e possibilitar uma proteção mais eficaz por intermédio de medidas sancionatórias atribuídas a esses sistemas, demonstrando que existe uma nítida relação de causa e efeito do reposicionamento de cada sujeito de direito na Sociedade Internacional, cuja efetividade somente pode ser concretizada se concebida a relativização da soberania do Estado, mérito outorgado, inexoravelmente, à Declaração Universal de 1948.

15 Thomas Buergenthal. International human rights, p. 17 Para Henkin, por mais de meio século, o sistema internacional tem demonstrado comprometimento com valores que transcendem os valores puramente "estatais". Notadamente os direitos humanos tem desenvolvido um impressionante sistema normativo de proteção desses direitos. (International law. p.2). 
Nesse sentido, há um reencontro com o pensamento kantiano com as ideias de moralidade e dignidade, direito cosmopolita e paz perpétua. Para Kant as pessoas, em geral qualquer espécie racional, devem existir como fim em si mesmo e jamais como meio, para ser arbitrariamente utilizado para este ou aquele propósito. Os objetivos tem um valor condicional, por serem irracionais, por isso são chamados "coisas", que são por outras equivalentes, enquanto que, os seres racionais são chamados de "pessoas", porque constituem um fim em si mesmo, tem um valor intrínseco absoluto, são insubstituíveis e únicos, não devendo ser tomados em si como meios, porque as pessoas são dotadas de dignidade, na medida em que possuem um valor intrínseco.

Para Kant, a autonomia ${ }^{16}$ é a base da dignidade humana e de qualquer criatura racional e a ideia de liberdade está intimamente conectada com a concepção de autonomia, por meio do princípio universal da moralidade que é fundamento de todas as açóes dos seres racionais ${ }^{17}$. Assim, o imperativo categórico universal, determina apenas que haja uma forma máxima, capaz de converter-se ao mesmo tempo, em uma lei universal.

\section{Objetivos}

Evidenciar que o esforço de reconstrução dos direitos humanos do Pós-Guerra, há de um lado, a emergência do Direito Internacional dos Direitos Humanos e de outro, a emergência da nova feição do Direito Constitucional ocidental, aberto a princípios e a valores, em ênfase no valor da dignidade humana.

Nesse sentido, no âmbito do Direito Internacional, começa a ser delineado o sistema normativo internacional de proteção aos direitos humanos, para proteger os direitos fundamentais e limitar o poder do Estado, mediante a criação de um aparato internacional de proteção de direitos.

Um sistema supranacional como o sistema interamericano de tutela dos direitos humanos significa que o não-cumprimento de uma das obrigaçóes internacionais estabelecidas por ele e em particular na Convenção de São José de Costa Rica gera a responsabilidade da Parte, que tem como consequência a obrigação de reparar integralmente todo prejuízo, tanto material como moral, que a ação ou omissão do Estado tenha causado.

Salientando-se que, a Convenção Americana obriga expressamente os Estados Membros, ou seja, os Estados que se comprometem a respeitar os direitos e liberdades nela

16 As teorias sobre direitos humanos tendem a enfatizar a importância e o valor da autonomia pessoal. (RAZ, J. Rights-based moralities. In: WOOD, Allen (ed.). Basic writings of Kant. New York : Modern Library, 2001, p.185-186, 192-193.

17 KANT, Immanuel. Fundamental principles of the metaphysics of morals. In: WOOD, 2001, ibid., p.178. 
reconhecidos e a garantir seu livre e pleno exercício a toda pessoa que esteja sujeita a sua jurisdição, sem discriminação alguma de acordo com o art. $1^{\circ}$ da Convenção, de modo que os mesmos Estados Membros têm de adotar as medidas legislativas ou de outro caráter que forem necessárias para fazer valer tais direitos e liberdades, se o exercício dos direitos e liberdades mencionados no art. $1^{\circ}$ não estiverem já garantidos pelas disposiçóes legislativas ou de outro caráter, conforme art. $2^{\circ}$ da Convenção de Direitos Humanos.

Por isso mesmo, os Estados Membros têm de remover todos os obstáculos que possam existir para que as pessoas possam desfrutar plenamente os direitos que a Convenção assegura, uma vez que é dever deles organizar todo o aparato governamental e, em geral, todas as estruturas por meio das quais se manifesta o exercício do Poder Público, de tal maneira que sejam capazes de assegurar juridicamente o livre e pleno exercício dos direitos humanos ${ }^{18}$. A partir dessas premissas, consideramos que delas derivam as consequentes obrigaçóes que se impóem aos Estados Membros implementar mecanismos que assegurem ao cidadão uma tutela judicial eficaz dos seus direitos.

Em relação ao princípio da tutela judicial efetiva, a mesma Convenção estabelece solenemente o direito de toda pessoa a ser ouvida, com as devidas garantias e dentro de um prazo razoável, por um juiz o tribunal competente, independente e imparcial, estabelecido antecipadamente pela lei, na formalização de qualquer acusação penal formulada contra ela, ou para a determinação de seus direitos e obrigações de ordem civil, trabalhista, fiscal ou de qualquer outro caráter de acordo com o art. 8.1 da Convenção e o direito a um recurso simples e rápido ou a qualquer outro recurso eficaz diante os juízes ou tribunais competentes, que a ampare contra atos que violem seus direitos fundamentais reconhecidos pela Constituição, pela lei ou pela presente Convenção, ainda que tal violação seja cometida por pessoas que atuem em exercício de suas funçôes oficiais nos termos do art. 25 da Convenção.

A conexão entre essas disposiçóes da Convenção é clara e expressamente reconhecida pela mesma Corte Interamericana na maior parte de sua jurisprudência, em relação à proteção judicial: em particular, o art. 25 se encontra intimamente ligado à obrigaçáo geral do art. 1.1 da Convenção Americana na atribuição de funções de proteção, ao direito interno dos Estados Membros, do qual se deduz que o Estado tem a responsabilidade de criar e consagrar normativamente um recurso eficaz e também de assegurar a devida aplicação de dito recurso por parte das suas autoridades judiciais.

Igualmente, a Corte deixou claro que para que se preserve o direito a um recurso eficaz nos termos do art. 25 da Convenção é indispensável que tal recurso seja tramitado conforme as regras do devido processo, consagradas no art. 8 da Convenção.

18 PÁDUA, Antônio de Maia e. Supervisão e cumprimento das sentenças interamericanas. Cuestiones constitucionales, p. 184. 
A Corte Interamericana sustentou que o art. 25 "constitui um dos pilares básicos não somente da Convenção Interamericana senão do próprio Estado de Direito em uma sociedade democrática no sentido da Convenção"19.

Seus conteúdos são muito característicos porque determinam expressamente que a garantia que seja estabelecida tem que ser “jurisdicional”, isto é, o Estado-Membro tem que escolher as medidas oportunas para fazer valer os direitos entre os instrumentos judiciais. Tal garantia encontra-se tutelada em cada uma das fases do processo, ou seja, no momento da interposiçáo, como durante o desenvolvimento do processo e no cumprimento das decisôes como se entende das letras a, b, c, da disposição citada.

Por essa razão, são impostas algumas qualificaçóes ao "recurso judicial”, que deve ser "simples, rápido, eficaz"; ainda que possa parecer que cada uma dessas qualificaçôes seja suficiente para cumprir a obrigação do art. 25, a mesma Corte em sua atividade consultiva e jurisdicional se ocupou de esclarecer que tem os três requisitos ao mesmo tempo, isso sem definir quais são os elementos necessários para determinar a simplicidade e a rapidez; com relação à eficácia, a posição da Corte em seus pronunciamentos, não somente em relação ao art. 25, mas também em relação aos arts. 1.1. e 8 nos parece ser mais abundante e clara, afirmando:

"Para que tal recurso exista, não basta que esteja previsto pela Constituição ou pela lei ou que seja formalmente admissivel, senão é necessário que seja realmente idôneo para estabelecer se ocorreu uma violação aos direitos humanos e prover o necessário para remediá-la. Não podem ser considerados eficazes aqueles recursos que, pelas condiçôes gerais do país ou inclusive pelas circunstâncias particulares de um caso dado, resultem ilusórios".

Isso pode ocorrer, por exemplo, quando sua inutilidade tenha sido demonstrada pela prática, porque o Poder Judicial carece da independência necessária para decidir com imparcialidade ou porque faltam os meios para executar suas decisões; por qualquer outra situação que configure um quadro de denegação de justiça, como acontece quando se incorre no retardo não justificado na decisão; ou, por qualquer causa, não se permita ao suposto lesado o acesso ao recurso judicial.

Essas três disposiçóes, em seu conjunto, contribuem para determinar quais são os mecanismos para que se tenha o controle e a proteção dos direitos humanos consagrados na Convenção Americana e permitem caracterizar quais são os recursos eficazes considerados necessários para proteger os direitos sem o prejuízo da existência de mecanismos de controle subsidiários no âmbito internacional, que só podem ser predispostos pelo Estado nacional.

19 ANDRADE, Isabela Piacentini. A execução das sentenças da Corte Interamericana de Direitos Humanos. Revista Brasileira de Direito Internacional, p.149-150 
Cabe precisar que, em nossa opiniáo, as instituiçóes processuais que atuem como procedimentos simples e breves e que tenham por objetivo a tutela dos direitos fundamentais, não necessariamente se identificam somente com o recurso de amparo entendido em um sentido clássico, de acordo com a Constituição do México de $1857^{20}$, porque o amparo não seria o único recurso que poderia ser estabelecido na organização interna dos Estados para cumprir com as obrigaçóes da Convenção.

De fato, nos parece ser correto sustentar como parece fazer o mesmo a Corte em seus pronunciamentos que o art. 25 tem um significado muito amplo e não só consagra o direito a um recurso simples, rápido e eficaz que se identifique com o amparo, senão que também o direito a outros recursos, diferentes, dentre os quais consideramos que devem estar os processos criminais para investigar delitos que implicam uma violação de um direito humano e todos os demais recursos necessários para garantir quaisquer direitos tutelados no sistema supranacional, como o Habeas Corpus e, em particular no Chile, o recurso de Proteção.

Segundo a interpretação que propomos, no sistema interamericano não se deseja vincular a proteção dos direitos humanos garantidos pela Convenção apenas a uma tipologia de recurso judicial, ou seja, ao modelo do amparo, senão que se deixaram as portas abertas a todas as medidas judiciais que alcancem as características da simplicidade, rapidez, eficácia e as características do devido processo e permitem ao Estado cumprir suas obrigaçóes internacionais.

Sob essa perspectiva, se o art. 1.1 propusesse tais obrigaçóes de modo geral, o art. 8 tutelaria especificamente o direito ao devido processo entre os demais direitos humanos protegidos pela Convenção, e o art. 25 estabeleceria o correspondente direito à tutela judicial eficaz, rápida e simples como garantia concreta a todos os direitos fundamentais, sejam proclamados ou reconhecidos pela Constituição, pelas leis nacionais ou mesmo pelo Pacto de São José.

\section{A Atuação da Corte Europeia de Direitos Humanos e a Garantia dos Direi- tos Indígenas no Contexto Internacional}

O sistema europeu de tutela dos direitos fundamentais foi desenvolvido pela Convenção Europeia para salvaguardar os Direitos do Homem e das Liberdades Fundamentais - CEDH, assinada em Roma em 1950, que pelo menos foi capaz de realizar um perfeito compromisso entre as exigências soberanas dos Estados e as exigências dos indivíduos porque impôs um sistema absolutamente original com relação às concepçóes clássicas do direito internacional e em particular ao vínculo de reciprocidade entre as Partes.

20 PÁDUA, Antônio de Maia e. Supervisão e cumprimento das sentenças interamericanas. Cuestiones Constitucionales, p. 191 
Esse tratado é o êxito fundamental do Conselho da Europa, já que nele são definidos os direitos e liberdades que os Estados Membros se comprometem a garantir a toda pessoa que pertença a sua jurisdição entre eles, o direito à vida, à proteção contra a tortura e tratos subumanos, à liberdade e à segurança, a um processo justo, ao respeito à vida privada e familiar, ao respeito à correspondência, à liberdade de expressão incluída a liberdade de imprensa, de pensamento, de consciência e de religião.

Desde 1950 até hoje, a Convenção teve muitas modificaçóes e alguns adendos para especificar os direitos protegidos e tornou sempre mais relevante o papel do indivíduo, uma vez que o cidadão já pode alcançar uma posição de paridade em relação aos Estados Membros perante o órgão principal de todo o sistema: o Tribunal Europeu de Direitos Humanos.

A função principal desse tribunal é assegurar o respeito aos compromissos estabelecidos para as Altas Partes Contratantes da Convenção segundo as condiçóes e os limites que ela define.

Trata-se, de fato, de um tribunal que intervém somente em extrema ratio, ou seja, eventualmente e subsidiariamente, uma vez que esgotadas todas as vias internas em cada Estado de proteçáo, segundo como estabelece o art. 35, inciso 1, CEDH.

Trata-se, principalmente, de uma tutela declarativa que é dirigida a verificar a violação dos direitos de pessoas físicas, associaçóes ou grupos, Estados Membros, e que pode ser dirigida contra comportamentos, atos administrativos, atos normativos e judiciais de um dos membros da Convenção; além disso, se caracteriza em particular depois da aprovação do Protocolo 11 pela expressa possibilidade de propor um recuso individual sem intervenção prévia da Comissão ou do Estado, o que faz da Corte Europeia de Direitos Humanos muito parecida a uma jurisdição de última instância.

A regra do "esgotamento prévio dos recursos internos", válida tanto para a jurisdição do Tribunal Europeu como para a generalidade dos sistemas de tutela supranacionais, encontra uma explicação e ao mesmo tempo um fundamento na obrigação dos Estados de cumprir com o art. 13, o qual confere a toda pessoa o direito a um recurso efetivo perante uma instância nacional, inclusive quando a violação aos direitos ou liberdades tiver sido cometida por pessoas que atuem no exercício de suas funçôes oficiais.

Dessas normas pode-se deduzir certa "complementaridade" entre o sistema supranacional e as organizaçóes nacionais com o fim comum da tutela dos direitos fundamentais concentrado sobre a figura do "sujeito tutelado".

Seria uma complementaridade requerida pelo mesmo sistema porque a Convençáo parece referir-se diretamente ao juiz nacional, o qual é e sempre permanece como o principal órgão que tutela os direitos fundamentais e, por isso, é quem deve aplicar o direito convencional. 
De fato, o cidadão membro de um dos países do Convênio Europeu goza do direito de ter acesso à justiça, tutelado pelo art. 6 da CEDH, que define o minimum das garantias da pessoa em relação ao exercício da jurisdição: trata-se, sinteticamente, do direito a um juiz imparcial, que opera em um processo equitativo e com duração razoável. Este é configurado como um direito subjetivo válido para toda situação subjetiva, também a de direito nacional, sem limitaçôes e distinções entre cidadãos, estrangeiros ou apátridas; além disso, esse mesmo direito está expressamente reconhecido seja a favor do sujeito interessado na resolução de uma controvérsia jurisdicional civil, seja à parte de um processo penal.

$\mathrm{O}$ que pode ser garantido por meio deste enunciado é não só o direito a um juiz “justo" ou a um processo "justo", mas também à possibilidade de "ter acesso ao juiz" que constitui a premissa de qualquer garantia dos procedimentos jurisdicionais; o acesso ao juiz é instrumental à finalidade de obter uma decisão jurisdicional embora se possa ter uma decisão de forma e não de fundo, por meio de um procedimento que comporte escutar as partes da controvérsia. Está implícito no acesso ao juiz, também o direito à "coisa julgada” ou à execução das decisóes jurisdicionais.

O direito de ter acesso à jurisdição não exclui a possibilidade de prover algumas fases não jurisdicionais no procedimento, sob a condição de que não substituam ou obstam os remédios jurisdicionais, mas que sirvam para completá-los e fazê-los mais eficazes. Igualmente, deve ser concebido o assunto da pluralidade de graus de juízo, os quais não são indicados taxativamente pela Convenção nem pela Corte em sua jurisprudência, mas devem respeitar as garantias do art. 6 em seu complexo.

A posição do Tribunal Europeu no contexto da proteção dos direitos fundamentais é complicada pelas relaçóes que, necessariamente, devem instaurar com a organização da Comunidade Europeia que concorre na mesma função, mediante a atividade de seus órgãos e, de modo particular, de sua jurisdição ${ }^{21}$.

De fato, foi o Tribunal de Justiça da Comunidade Europeia de Luxemburgo, em sua própria jurisprudência antes que qualquer acordo entre as partes, que revelou como insuficiente a ideia de tutelar somente direitos e liberdades conexos com as finalidades de integração econômica, a qual se encontrava no Tratado que instituiu a Comunidade Europeia.

Por essa razão, houve as modificaçóes aportadas com o Tratado de Maastricht por meio do qual a União Europeia se obrigava a respeitar os direitos fundamentais considerados como princípios gerais do direito comunitário e, em particular, o art. 6.2 do Tratado Amsterdã, o qual, de maneira explícita e incontrovertível, afirma:

21 ANDRADE, Isabela Piacentini. A execução das sentenças da Corte Interamericana de Direitos Humanos. Revista Brasileira de Direito Internacional, p. 159. 
"A União respeitará os direitos fundamentais tal e como eles são garantidos no Convênio Europeu dos Direitos Humanos e das Liberdades Fundamentais assinado em Roma no dia 4 de novembro de 1950, e tal como resultam das tradiçóes constitucionais comuns aos Estados Membros como princípios gerais do Direito Comunitário”.

Em consequência, temos que no contexto europeu existem duas jurisdiçôes, dois tribunais supranacionais, duas estruturas com finalidades diferentes, que exercitam a mesma tutela talvez realmente para os mesmos direitos fundamentais e sobre a base do mesmo parâmetro, ou seja, a Convenção de Roma de 1950.

No primeiro período o Tribunal de Justiça, superando os limites de sua própria competência e ingressando no território da $\mathrm{CEDH}$, ignorou a jurisprudência já consolidada do Tribunal Europeu dos Direitos Humanos, sucessivamente teve de enfrentar a necessidade de instaurar relaçóes dinâmicas com a outra jurisdição.

Em muitas de suas decisóes o Tribunal de Luxemburgo tem demonstrado a tendência a uma maior atenção à jurisprudência de Estrasburgo ${ }^{22}$, apesar de nem sempre haver uma coincidência de pontos de vista e de, frequentemente, haver contrastes e contradiçóes.

Uma ulterior forma de integração entre os sistemas supranacionais de tutela dos direitos fundamentais e entre estes e os sistemas nacionais de cada Estado da União Europeia foi possível depois da proclamação da Carta dos Direitos Fundamentais da União Europeia em ocasiāo do Conselho da Europa de Niza em dezembro de 2000.

Embora, em sua gênese, esse documento tenha sido concebido com puro significado político simbólico, primariamente "compilador" dos elementos comuns das tradiçôes constitucionais dos Estados Membros, a sucessiva introdução desse instrumento em um dos artigos do Tratado que institui uma Constituição para a Europa, assinado em Roma no dia 29 de outubro de 2004, faz com que seja inevitável e comprovado que essa declaração de direitos possa assumir uma força jurídica vinculante desde o momento em que entrar em vigor a Constituição Europeia.

A discussão acerca de direitos indígenas compreendendo os sistemas jurídicos de povos indígenas, no Brasil, ganhou novos contornos a partir da Constituição de 1988, especialmente, por deixar evidente que se deve levar a sério a diversidade cultural, rompendo, pelo menos na "inscrição" com o descompromisso político institucional.

A atual Constituição, ao reconhecer aos povos indígenas o direito à organizaçáo social, costumes, línguas, crenças e tradiçôes, afirmou o direito dos povos nativos à diferença, forjado pela existência de diversidades culturais, rompendo o paradigma da integraçáo e da assimilação que até então dominava o ordenamento jurídico brasileiro.

22 ANDRADE, Isabela Piacentini. A execução das sentenças da Corte Interamericana de Direitos Humanos. Revista Brasileira de Direito Internacional, p. 162. 
A conquista histórica dos direitos na Constituição promulgada em 1988 mudou substancialmente o destino dos povos indígenas do Brasil. De transitórios e incapazes passaram a protagonistas, sujeitos coletivos e sujeitos de direitos e de cidadania brasileira e planetária.

No entanto, quanto ao direito dos povos indígenas de manter seus próprios sistemas de justiça ou, em outras palavras, seus próprios Direitos ainda não houve a quebra dos antigos padróes; o presente guarda continuidades com o passado, no qual a ordem institucional e jurídica subjugava os povos indígenas. Hoje, como antes, os direitos diferenciados dos povos indígenas não são respeitados.

No Brasil, ainda que a legislação infraconstitucional através do Estatuto do Índio ${ }^{23}$ "tolere" para utilizar a expressão da lei, através da aplicação das normas indígenas ${ }^{24}$ de forma secundária quando a lei for omissa ou inferior desde que não contrarie as normas estatais, os tribunais, mesmo em delitos praticados dentro das terras indígenas e entre indígenas, têm-se considerado pertinentes para o julgamento. Afinal, direitos não podem ser tomados via tolerância, devem ser respeitados sempre!

Em outros países da América Latina, a situação dos povos indígenas não é diferente do que ocorre no Brasil. No caso do Paraguai a situação que se pretende analisar no momento apesar do reconhecimento de direitos formais pela Constituição, as violaçóes das formas de vidas diferenciadas e dos próprios sistemas jurídicos desses povos são constantes.

O Direito, assim como a lei, é uma construção histórica, resultado da atividade humana e, nesse sentido, sujeito às lógicas da história e do poder, constituindo-se, desse modo, em espaço privilegiado de manobras, isto é, de inclusão versus exclusão, de legitimidade versus ilegitimidade, de Direitos versus usos e costumes (direito consuetudinário). Criam-se, assim, discriminaçóes jurídicas, manifestaçóes do colonialismo interno e das constantes tensóes entre colonizadores e colonizados, espaço em que o estatal é hegemônico diante do náo estatal.

Nesse sentido, o uso de expressóes tomo direito consuetudinário, usos e costumes ou resolução alternativa de conflitos de nenhuma maneira assegura a real coexistência de Direitos em situação de igualdade; ao contrário, ao dizer que as formas de jurisdição e administração de justiça são válidas sempre que não sejam contrárias à Constituição ou

23 O projeto referente ao novo Estatuto do Índio tramita no Congresso nacional há mais de 21 anos. Aliás, é hora de pensar em criar um Estatuto dos Povos Indígenas com a participaçáo dos interessados, assim se evitariam as equivocadas interpretaçôes do estatuto que mesmo vigente foi "anulado" pela Constituição brasileira de 1988 .

24 Diz o Estatuto do índio: "Art. 57. Será tolerada a aplicaçấo, pelos grupos tribais, de acordo com instituiçôes próprias, de sançôes penais ou disciplinares contra os seus membros, desde que não revistam caráter cruel ou infamante, proibida em qualquer caso a pena de morte" Conferir: BRASIL. Lei $\mathrm{N}^{\circ}$. 6.001/1973. Disponível em htpp:// www.presidencia.gov.br/legislacao. 
às leis limita-se a inclusão do Direito indígena e predefine-se o controle e a subordinação. Nas entrelinhas o Estado expressa monopólio da norma jurídica, mostrando quão longe se está do autêntico pluralismo jurídico, uma vez que mantém o direito indígena subordinado ao direito estatal. O colonialismo jurídico a que estão submetidos os povos indígenas demonstra a incapacidade de coexistência na diversidade, tanto política como social e jurídica.

Apesar do reconhecimento formal da diferença dos povos indígenas na Constituição brasileira, a violação de direitos ainda se faz sentir e as situaçôes de fricçôes interjudiciais ${ }^{25}$ se fazem presentes no cotidiano Latino Americano. A expressão refere-se à contraposição do Direito indígena ao Direito estatal, sob o "sistema interétnico" forjado pela tensa convivência entre duas populaçóes vinculadas por interesses diametralmente opostos; a insubordinação do Direito indígena revela a instabilidade do sistema.

Mostra-se, no entanto, que existem mecanismos internos e/ou externos que garantem a efetivação da diferença não como desigualdade, e sim como oportunidade de autodeterminação desses povos, especialmente pela capacidade de mobilização do movimento indígena.

\section{Conclusões}

Os Direitos Humanos dispóem de um conjunto de direitos inerentes ao cidadão que resultam de um processo permanente de evolução, desenvolvimento e consolidação, guardando entre si a indivisibilidade, a interdependência e a universalidade.

Rever a história da construção dos direitos humanos ao longo do processo de desenvolvimento é essencial à tutela dos direitos fundamentais, em caráter universal, levando em consideração o advento da Declaração Universal de 1948, em que o indivíduo foi inserido em um novo contexto junto à Sociedade Internacional, sendo evidenciado como o pleno sujeito de direitos.

Os direitos humanos se consolidaram com a segunda guerra mundial, tornando-se consagrados nos planos normativos como objeto de demandas sociais, que pleiteavam a proteção não apenas dos direitos individuais, mas, sobretudo, de toda sociedade. Para tanto, havia a necessidade da construção de sistemas internacionais que promovessem e

25 Conforme explica Moreira (2005), o conceito de "fricção interjudicial" foi inspirado no conceito de "fricção ínterétnica” de Cardoso de Oliveira (1972). Segundo este autor, fricção interétnica refere-se ao “... ao contato entre grupos tribais e segmentos da sociedade brasileira, caracterizados por seus aspectos competitivos e, no mais das vezes, conflituosos, assumindo esse contato muitas vezes proporçóes 'totais; i. e., envolvendo toda a conduta tribal e não-tribal que passa a ser moldada pela situaçáo de fricçáo interétnica” (1972: 128. Grifos no original.) Conferir: CARDOSO OLIVEIRA, Roberto. O índio e o mundo dos brancos. Uma interpretação sociológica da situação dos Tukúna. 2a ed. São Paulo, Livraria Pioneira Editora, 1972. 
garantissem os direitos humanos de modo a torná-los valores universais e devidamente observado pelos ordenamentos internos.

A orientação hegemônica liberal, por sua vez, a partir de uma fundamentação teórica mais elitista e pluralista, baseada, por sua vez, no conceito negativo de liberdade, veicula um modelo de democracia procedimental, a princípio, representativo e liberal, mas que, em última instância, tem objetivos gerenciais para a garantia de uma governança global capitalista. Assim, há a total proeminência da dimensão procedimental de democracia, mesmo que, posteriormente ela venha a facilitar a implementação das outras dimensóes, participativa e social. Diferentemente desse posicionamento, advoga-se, de forma contra-hegemônica o estabelecimento de um círculo virtuoso e necessário, entre os aspectos formal, participativo e social. Da mesma forma, os direitos fundamentais seriam, garantidamente, os direitos civis e políticos, ou seja, os já consagrados direitos da liberdade, essa, negativamente defendida. A terceira geraçáo dos direitos humanos, o direito ao desenvolvimento, também sofre uma redução no seu conteúdo, estando quase sempre associado a critérios como o crescimento do PIB apenas. A segunda questão versa sobre o tipo de relação entre a democracia, os direitos humanos e ordem internacional. Há uma tendência, ainda dominante, mas que já vem encontrando resistência dos fóruns mundiais, a exemplo do famoso relatório de 2000 do PNUD e da própria Carta Democrática da OEA .É a tendência de se separar democracia, direitos humanos e desenvolvimento. Caso ainda mais facilitado pela experimentação, nos dias de hoje, do chamado "estado de exceção permanente" que permite a restrição de direitos humanos, seja tanto no âmbito interno quanto externo, a fim de se enfrentar situaçóes de conflito. É interessante e contraditório o que se consegue depreender dos discursos que legitimam as recentes invasóes americanas quando neles se restringe a democracia, ou o próprio Estado de Direito, interno e internacional, alegando-se a proteção da mesma democracia. Algumas das teorias contra-hegemônicas de autores neogramscianos como Craig Murphy e Robert Cox, além de Stephen Gill, representam um tipo específico de abordagem e levam à consideração da democracia como um conceito dinâmico a ser estabelecido em cada realidade de Estado, não correspondendo, diretamente, nem sequer a uma modalidade republicana, ou muito menos liberal. Essa concepção de democracia, entretanto, deve atender a requisitos essenciais: a presença de um círculo virtuoso entre os aspectos procedimental, participativo e social da democracia, capaz de manter um canal aberto e transformador com as diversas dimensôes da sociedade civil até no plano transnacional; e uma relação necessária entre a democracia, os direitos humanos e a perspectiva do desenvolvimento.

Todos, entretanto, munidos de um significado mais estendido, já apresentado. Reconhece-se, também, e esse dado é fundamental, que cada sociedade deve encontrar o seu modelo a partir das premissas elencadas. $\mathrm{O}$ mais importante é que os canais de comunicação entre o Estado e a sociedade civil, interna e transnacionalmente, também favorecidos 
pelas organizaçóes internacionais, devem ser mantidos abertos, a fim de que se estabeleça uma dinâmica "de baixo para cima”, capaz de constituir um espaço público verdadeiramente representativo dos diferentes elementos de poder. Este espaço público renovado é a arena necessária, em uma perspectiva nacional, para a formulação de consensos que irão viabilizar, por sua vez, a efetivação de escolhas realmente democráticas, para a construção de significados para a atuação das diferentes esferas do poder público, inclusive do Judiciário, na busca de efetivação e realização dos Direitos Humanos, na sua amplitude máxima e possível.

Salientando-se que, os desafios da justiça internacional em matéria de direitos humanos estabelece também um marco na tensão entre o direito da força e a força do direito, dificultando assim, a construção efetiva dos direitos humanos no Estado Democrático de Direito.

Como observa Norberto Bobbio, a garantia dos direitos humanos no plano internacional só será implementada quando uma "jurisdição internacional se impuser concretamente sobre as jurisdiçôes nacionais, deixando de operar dentro dos Estados, mas contra os Estados e em defesa dos cidadãos"26.

Assim, a análise das normas e do Sistema Europeu de Direitos Humanos, o direito de acesso à justiça está garantido ao mesmo tempo em duas diferentes sedes e em um nível duplo na perspectiva comunitária, por um lado, os indivíduos podem ter acesso diretamente às instituiçóes jurisdicionais da União Europeia como o Tribunal de Primeiro Grau e Tribunal de Justiça da Corte Europeia e por outro lado, os juízes nacionais podem tutelar diretamente as situaçóes jurídicas subjetivas de direito comunitário; em outra perspectiva, a da Convenção, ao acesso direto à jurisdição é somada à possibilidade de uma aplicação direta das normas convencionais em virtude de cláusulas muito amplas presentes nas Constituiçóes nacionais que permitem conceber diversamente o direito supranacional na hierarquia das fontes do direito e de suas interpretaçóes por parte da Corte nos processos internos de cada Estado.

Esta última possibilidade é a que a doutrina europeia considera como a mais importante para uma integração entre as organizaçóes estatais e as nacionais: a jurisprudência da Corte de Estrasburgo é configurada como o meio pelo qual é possível criar uma uniformidade de interpretação dos direitos humanos em toda Europa.

Além disso, segundo a tese de Peter Häberle que parte da impostação filosófica de Karl Raimund Popper, o direito internacional é "direito universal da humanidade" e a interpretação dos direitos fundamentais é necessariamente "um desafio aberto" para usar a expressão de Ralf Dahrendorf e permite o nascer de uma comunidade "transnacional"

26 BOBBIO, 1992, op cit., p.25-47. 
entre os intérpretes dos direitos humanos, ou seja, um "direito comum" das liberdades fundamentais.

Parece-nos impossível que tais objetivos possam ser conseguidos sem uma cooperação entre os estudiosos e uma integração das jurisprudências, mas o que queremos destacar nesta investigação científica é que poderia ser igualmente útil aproximar os diferentes sistemas de tutela o máximo possível. Para isto serve a comparação, para que seja possível ver quais são os mecanismos que melhor garantem uma tutela eficaz e quais são os que faltariam ou que seria útil introduzir.

A ausência de um acesso "indireto" ao sistema europeu, o qual, contrariamente, é uma previsão crucial do sistema interamericano de proteção dos direitos humanos, parece-nos um dado sobre o qual seria útil refletir.

Não é um caráter sem relevância nesse sistema e no contexto dos Estados latino-americanos, onde a violação de direitos humanos mais comum é a impunidade daqueles que foram responsáveis por abusos contra a humanidade e contra pessoas que não puderam porque a morte lhes impediu de fazê-lo usufruir as tutelas da Comissão e da Corte Interamericanas de Direitos Humanos que, mesmo que existissem, não tinham reconhecimento adequado.

A competente doutrina póe em evidência que, apesar de a execução das sentenças do órgão jurisdicional por ambos os sistemas europeu e interamericano ser algo que o Estado tenha de cumprir e não mais que isso, a Corte Interamericana em algumas sentenças importantes condenatórias dispôs uma indenização econômica para as vítimas, se pudesse superar o obstáculo da falta de normas internas que regulamentem o cumprimento das recomendaçôes da Comissão e das sentenças da mesma Corte outra doutrina se refere em particular aos citados casos por todas as consideraçóes que precedem, pode-se concluir que existem elementos suficientes para uma comparação entre os dois sistemas analisados porque, apesar das diferentes histórias e das configuraçóes singulares, apresentam muitos pontos de contato e muitas semelhanças e se aproximam mais quando parecem estar distantes.

As políticas estatais de caráter universal não tem sido suficientes para a redução da desigualdade social e a exclusão cultural, causando um impacto desproporcionalmente lesivo as minorias e aos grupos vulneráveis, contribuindo para a reprodução e o aprofundamento dos mecanismos de hierarquização existentes na sociedade.

Os objetivos previstos no art. $3^{\mathrm{a}} \mathrm{da} \mathrm{CRFB} / 88$, de que são exemplos a erradicação da pobreza e da marginalização e a redução de desigualdades sociais e regionais, só poderão ser atingidos se os Poderes Públicos levaram em conta a diminuição das desigualdades desde os pontos de partidas. Em outras palavras, não adianta esperar os resultados da implementação de uma política pública se as condições para a fruição dos direitos que ela vem garantir não forem oferecidas aos grupos mais vulneráveis. 
Assim, é preciso levar em conta que o status na sociedade pluralista, como diria Fraser, não pode ser reduzido a uma questão de classe. Outros fatores, além da má distribuição dos recursos econômicos, contribuem para um tipo de injustiça como a exclusão por razóes de não reconhecimento das diferenças culturais.

Se o objetivo é combater as desigualdades sociais e promover o reconhecimento do direito à diferença, as políticas universalistas determinadas pelos representantes eleitos pelo povo devem conviver com a implementação de mecanismos de proteção diferenciados que garantem o respeito a grupos vulneráveis, o reconhecimento de sua participação na sociedade em igualdade de condiçóes com os grupos majoritários e a distribuição mais justa dos recursos de poder e bens socialmente produzidos.

Trata-se da dupla dimensão da justiça, segundo a qual somente a redistribuição somada ao reconhecimento produz a realização da igualdade em seu sentido mais amplo, visando maior proteçáo possível às minorias, em especial aos povos indígenas, assegurando maior efetividade de Direitos àqueles que estiveram em sua grande parcela à margem do processo de desenvolvimento social, político e econômico.

Por fim, a fruição dos Direitos Humanos proclamados formalmente numa Constituição ou num Tratado Internacional não ocorre factualmente em espaços políticos que não sejam democráticos. E de nada serve uma Constituição que não seja sentida, vivida e praticada pela população e pelas autoridades constituídas. Logo, o pleno gozo dos Direitos Humanos depende, no dia-a-dia, da capacidade de participação política e cidadã da população para a construção de uma sociedade efetivamente democrática.

\section{Referências}

ALBUQUERQUE MELO, Celso. Curso de Direito Internacional Público. 13a edição. Rio de Janeiro: Renovar, 2001.

ALEXY, Robert. Teoria dos direitos fundamentais. Tradução de Virgílio Afonso da Silva. São Paulo: Malheiros, 2008.

ALMEIDA, Fernando Barcellos de. Teoria Geral dos Direitos Humanos. Porto Alegre: Sergio Antonio Fabris, 1996.

ANDRADE, José Carlos Vieira de. Os direitos fundamentais na constituiçáo portuguesa de 1976. 2.ed. Coimbra: Almedina, 2001.

BARIÉ, Cletus Gregor. Pueblos Indígenas y Derechos Constitucionales en América Latina: un panorama. 2a Ed. Versión eletrônica, 2004.

BASTOS, Celso Ribeiro. Dicionário de direito constitucional. São Paulo: Saraiva, 1994. 
BOBBIO, Norberto. A Era dos direitos. Trad. de Carlos Nelson Coutinho. Nova ed. 5. tir. Rio de Janeiro: Elsevier; Campus, 2004.

CONTI, Irio Luiz (Coord.) Direito Humano à Alimentaçáo Adequada. Rio de Janeiro: Lúmen Juris Editora, 2007.

COMPARATO, Fábio Konder. A afirmação histórica dos direitos humanos. São Paulo: Saraiva, 2008.

PIOVESAN, Flávia. Direitos humanos e direito constitucional internacional. São Paulo: Saraiva. 2009. 10. ed. São Paulo: Saraiva, 2009.

HENKIN, Louis et. al. International Law, Cases and Materials. $5^{\text {th }}$. ed. New York : West, 2009. (American Casebooks Series).

IKAWA, Daniela (Coord.) Direitos Humanos - Fundamentos, Proteçáo e Implementação - Perspectivas e Desafios Contemporâneos. Vol. II. Curitiba: Juruá Editora, 2008.

JAYME, Fernando G. Direitos humanos e sua efetivaçáo pela Corte Interamericana de Direitos Humanos. Belo Horizonte: Del Rey, 2005.

SANTOS, Milton. Por uma outra globalização: do pensamento único à consciência universal. Rio de Janeiro: Record, 2000.

WOLKMER, Antonio Carlos. Síntese de urna História das Idéias Jurídicas da Antiguidade Clássica a Modernidade. Florianópolis: Fundação Boiteux, 2006.

LEAL, Rosemiro Pereira. Teoria processual da decisão jurídica. São Paulo: Landy, 2002.

LEITE, Jose Rubens Morato. (Orgs.) Os “Novos” Direitos no Brasil: Natureza e perspectivas. São Paulo: Saraiva, 2003.

MAZZUOLI, Valério de Oliveira. Curso de direito internacional público. 2. ed. São Paulo: Editora Revista dos Tribunais, 2007.

MELLO, Celso D. Albuquerque. Direito internacional americano. Rio de Janeiro: Renovar, 1995.

MORAIS, José Luis Bolzan de. As crises do Estado e da constituição e a transformação espacial dos direitos humanos. Porto Alegre: Livraria do Advogado, 2002.

SANTILLI, Juliana. In PIOVESAN. Direitos Humanos - Fundamentos, Proteção e Implementação - Perspectivas e Desafios Contemporâneos. Vol. II. Curitiba: Juruá Editora, 2008, p. 341.

TRINDADE, Antonio Augusto Cançado. Direitos humanos e desenvolvimento: evoluçáo e perspectiva do direito ao desenvolvimento como direito humano. Tratado de direito internacional dos direitos humanos. Porto Alegre: Sergio Fabris, 1997. V.2. p. 261-329. 
O estado e as relaçóes internacionais: o domínio reservado dos estudo na prática das naçóes unidas e organizaçóes regionais. Brasília: Universidade de Brasília, 1979.

A proteção internacional dos direitos humanos: fundamentos jurídicos e instrumentos básicos. São Paulo: Saraiva, 1991.

O esgotamento de recursos internos no direito internacional. 2.ed. atual. Brasília: Universidade de Brasília, 1997.

A proteção internacional dos direitos humanos e o Brasil. 2.ed. Brasília: UnB, 2000.

SILVA, José Afonso da. Curso de direito constitucional positivo. 13. Ed. São Paulo: Malheiros, 1997.

SILVA JR, Hédio. Direito de igualdade racial: aspectos constitucionais, civis e penais: doutrina e jurisprudência. São Paulo: Editora Juarez de Oliveira, 2002.

VIEIRA, Liszt. Cidadania e globalização. Rio de Janeiro: editora Record, 1997.

OEA. Comissáo Interamericana de Direitos Humanos. Relatórios anuais. Disponíveis em: http://www.cidh.org, acessado em 15 de maio de 2015.

ORGANIZAÇÃO DOS ESTADOS AMERICANOS (OEA). Carta da OEA. Assinada em Bogotá, Colômbia, em 30 de abril de 1948. aprovada pelo Brasil através do Decreto Legislativo 64, de 1949. Promulgada em 1951.

ORGANIZAÇÃO DOS ESTADOS AMERICANOS (OEA). Convenção Americana de Direitos Humanos. Pacto de San José da Costa Rica. Adotada na Conferência Especializada Interamericana sobre Direitos Humanos, ocorrida em San José em 1969. Aprovada pelo Brasil pelo Decreto Legislativo 27, em 1992. Promulgada pelo Decreto Executivo 678, de 1992.

RESEK, José Francisco. Direito internacional público. 9.ed. rev. São Paulo: Saraiva, 2002.

ROBLES, Gregorio. Los derechos fundamentales y La ética en la sociedad actual. Madrid: Civitas, 1992.

SOARES, Mário Lúcio Quintão. Direitos fundamentais e direito comunitário: por uma metódica de direitos fundamentais aplicada às normas comunitárias. Belo Horizonte: Del Rey, 2000.

TOMUSCHAT, C. Human Right: Between idealism and realism. Oxford: Oxford University Press, 2008.

TRINDADE, Antônio Augusto Cançado. A humanizaçáo do direito internacional. Belo Horizonte: Del Rey, 2006. 
TRINDADE, Antônio Augusto Cançado. A proteçáo internacional dos direitos humanos e o Brasil (1948-1997): as primeiras cinco décadas. Brasília: Universidade de Brasília.

WATSON, Adam. A evolução da sociedade internacional: uma análise histórica comparativa. Brasília: UnB, 2004. 